\title{
PANCITOPENIASECONDARYTOTHEUSEOFLOW-DOSEMETHOTREXATE IN A PATIENT WITH RHEUMATOID ARTHRITIS: CASE REPORT
}

\author{
Rebecca de Souza Costa ${ }^{1, \star}$, Lucas Siqueira Geber Oliveira ${ }^{1}$, Andre Machado Furtado ${ }^{1}$, Gloria Maria de Oliveira ${ }^{1}$ \\ 1.Hospital Federal do Andaraí, Rio de Janeiro (RJ), Brazil. \\ ${ }^{*}$ Corresponding author: rebecca.s.costa@hotmail.com
}

\section{BACKGROUND}

Methotrexate (MTX) is an antagonistic drug of folic acid metabolism and is used as the first line of treatment of rheumatoid arthritis (RA) as a disease-modifying drug. The most common side effects attributed to this drug include the gastrointestinal tract, such as oral mucositis, nausea, vomiting, and diarrhea. However, rarely, more serious effects may be present, such as hematological toxicity, including pancytopenia (about 3\%). In this article, we will bring the case report of a patient with RA who developed severe pancytopenia secondary to the use of MTX in subdose.

\section{CASE REPORT}

A 62-year-old white woman, born in Rio de Janeiro, diagnosed with RA for 5 years, without other comorbidities. Three months ago, treatment with MTX $7.5 \mathrm{mg} /$ week and prednisone $5 \mathrm{mg} /$ day was instituted. She denied use of folic acid supplementation. She was admitted to the Emergency Department with epistaxis, gingival bleeding, subconjunctival hemorrhage and oral stomatitis. Laboratory tests for admission showed Hb $11.1 \mathrm{mg} / \mathrm{dL}$; platelets 3,000 $\mu \mathrm{L}$, leukocytes $700 \mu \mathrm{L}$; serum creatinine $1.24 \mathrm{mg} / \mathrm{dL}$, serum albumin $2.1 \mathrm{mg} / \mathrm{dL}$. She developed worsening anemia ( $\mathrm{Hb} 7.4 \mathrm{mg} / \mathrm{dL}$ ), maintaining thrombocytopenia (11,000 $\mu \mathrm{L}$ ), leukopenia $(1,900 \mu \mathrm{L}-304$ neutrophils) and bleeding externalization requiring platelet transfusion and initiation of antibiotic therapy by severe neutropenia. After suspension of MTX, a 4-day treatment was instituted with filgrastim $300 \mathrm{mcg} /$ day, 12 days methylprednisolone $80 \mathrm{mg} /$ day and onset of folic acid supplementation. After 15 days of hospitalization, the patient evolved with clinical and laboratory improvement ( $\mathrm{Hb}: 10.1 \mathrm{mg} / \mathrm{dL}$; platelets: $219,000 \mu \mathrm{L}$; leukocytes: 10,100 $\mu \mathrm{L}$ ), being discharged from the hospital with referral to the rheumatology outpatient clinic, and treatment with hydroxychloroquine $400 \mathrm{mg} /$ day was started.

\section{CONCLUSION}

Although hematological toxicity as an adverse effect to the use of MTX is rare, the most commonly associated risk factors are: advanced age, renal failure, hypoalbuminemia, obesity, malnutrition and absence of folic acid supplementation. The patient had two of the described risk factors: absence of folic acid replacement and hypoalbuminemia. In this case, it is worth emphasizing the importance of the attending physician in prescribing folic acid supplementation and in making the patient aware of its use, in addition to monitoring serum levels of albumin and renal function, preventing more serious events. 